\title{
Heteroside-321 Hepatoregeneration Activity In Cases Of Hepatitis Inducted By Local Hyperthermia
}

\author{
Kabachnyy V.I.*Bozhkov A.I. Kabachnaya I.V. \\ National University of Pharmacy, 53 Pushkinskaya Str., 61002 Kharkov, Ukraine \\ *Research Institute of Biology, V.N. Karazin National University of Kharkov, 4, Svobody Sq., 61022 \\ Kharkov, Ukraine.
}

\begin{abstract}
Lipid metabolism and proliferative activity of rat hepatocytes after induction of hepatitis by local hyperthermia and the effect of heteroside-321 on collagen contents and the rate of DNA synthesis in liver and spleen cells in animals with induced hepatitis were studied. The proliferation rate was determined using radioactive precursors of ${ }^{3} \mathrm{H}$-thymidine, and the rate of lipid synthesis was assessed by incorporation of the radioactive ${ }^{14} \mathrm{C}$ sodium acetate. Separation of lipids into fractions was carried out by the thin-layer chromatography. The collagen content was determined by the concentration of hydroxyproline, and the functional activity (and restoration of the functional activity of liver?) was determined by the duration of hexenal sleep. It was shown that local hyperthermia was accompanied by an increase in the content of collagen in the liver by 55\%, and the content of neutral lipids in the liver and their metabolism also increased. Along with these processes, the antitoxic function of the liver decreased, as evidenced by an increase in the duration of hexenal sleep. Intraperitoneal administration of Heterozide-321 to animals with hepatitis significantly increased the rate of the processes of regeneration in the liver 48 hours after the administration. Therefore, the heterozides can be used as activators of regeneration processes.
\end{abstract}

Keywords: Heterozide-321, hepatocytes, proliferation activity.

\section{Introduction}

As it is known, hepatitis is an acute or chronic inflammation of a liver. Factors that induce hepatitis are very diverse, which is a theoretical basis for the classification of this pathology. Currently viral, toxic, drugs and autoimmune hepatitis are distinguished [1]. This kind of pathology can be developed under the influence of physical factors. The model of hyperthermia hepatitis is of the greatest interest for the oncotherapy methods. It is known that tumor cells have a greater sensitivity to the action of an elevated temperature $\left(42-45{ }^{\circ} \mathrm{C}\right)$ than a normal tissue [1-3]. The mechanisms of temperature influence on cells and tissues fundamental research allowed us to develop an arsenal of effective anticancer hyperthermia methodologies [4,5], which currently are still in the center of attention of oncologists, that search for ideal schemes and ways to use them effectively [6]. A lot of experts consider that the most promising in this regard is the local hyperthermia, which is based on a system SelectoTherm (capacitive electro hyperthermia) [7]. The cytotoxic effect of elevated temperature $\left(42{ }^{\circ} \mathrm{C}\right.$ or more) is associated with an inflammatory process [8], synthesis of specific heat shock proteins [9], change in membranes conformational state, inhibition of DNA synthesis [10]. This adversely affects not only cancer but also normal cells, particularly their ability to further proliferation (regeneration), because they are particularly sensitive to temperature in S-period of the cell cycle [11]. The interrelation of these processes can lead to aggravation of pathology (development of hepatitis $\leftrightarrow$ fibrosis $\rightarrow$ cirrhosis) or to restoration of the organ due to regeneration of the functionally active hepatocytes or stem cell activation. Mechanisms of cells heat damage and their relation to the regeneration processes are not fully discovered. The understanding of mechanisms of these processes is necessary not only for the practical medicine, but also for understanding the influence of hyperthermia on the cell function. The effect of local liver hyperthermia on the lipid metabolism, liver regeneration, DNA synthesis rate in rat spleen cells and influence of Heteroside 321 on these parameters were studied.

\section{Materials And Methods}

Experimental hepatitis was simulated using local liver hyperthermia [12]. Local liver hyperthermia was carried out as follows. All operations were performed on an anesthetized animal. The abdominal cavity of the animal was opened, without damaging the integral state of the liver and the liver blood vessels, extracted two lobes of the liver and placed into a thermostatic cell filled with saline, at the temperature of $45 \pm 1{ }^{\circ} \mathrm{C}$ for 10 min. After returning of the liver to the peritoneal cavity peritoneum was sutured and after 24 hours inflammatory process in the liver were developed[13], which intensity was evaluated by the content of collagen contents and detoxication function of liver. Experiments were performed at 3 months male rats Wistar. The control animals (which received saline) and the experimental (which received the heterosides-321) were divided 
into 4 experimental groups, respectively, which were killed after $24 \mathrm{~h}$ ( 1 group), $48 \mathrm{~h}$ ( 2 group), $72 \mathrm{~h}$ (3 group) and $96 \mathrm{~h}$ (4 group) after the introduction of heterozide-321 or saline.

1.1. Collagen content determination. The content of collagen in liver was determined as described in [14]

1.2. Liver detoxification function was evaluated by the duration of a hexenal sleep [15].

1.3. The content and the rate of lipid synthesis were determined. When determining the rate of the lipid synthesis the animals were injected with $\left[{ }^{14} \mathrm{C}\right]$ sodium acetate $(5.5 \mathrm{MBq} / 100 \mathrm{~g}$ body mass) $60 \mathrm{~min}$ to sacrifice. Microsome and cytosol fractions were isolated from the liver of control and experimental rats following perfusion with $0.25 \mathrm{M}$ sucrose as described elsewhere [16]. Lipids were extracted from serum, microsomes, and cytosol [17]. The lipids were fractionated by thin-layer chromatography on Silufol plates (Czechoslovakia) using hexane acetate acid diethyl ester-methanol-glacial acetic acid (9:2:0:2:0.3 v/v) followed by qualitative and quantitative analysis of the fractions thus obtained and evaluation of their specific radioactivities as described elsewhere [18].

Lipoproteins were isolated from the cytosol as described [17]. For this purpose, the $\mathrm{pH}$ of the cytosol was brought to 5.1 (using $0.1 \mathrm{M} \mathrm{HCl}$ ) and the cytosol was incubated for $2 \mathrm{~h}$ at $4{ }^{\circ} \mathrm{C}$. The pellet was isolated by centrifugation at $12000 \mathrm{~g}$ for $20 \mathrm{~min}$ at $4{ }^{\circ} \mathrm{C}$. The supernatant was collected and its $\mathrm{pH}$ adjusted to $7.4(0.2$ M Tris), then the lipoproteins were precipitated by ammonium sulfate at $90 \%$ saturation. The protein content of the lipoprotein pellet thus obtained was determined by the Lowry method, while the lipids were extracted by a general procedure; the lipid content was assessed per mg of protein of the lipoprotein fraction.

The radioactivity of labeled compounds was determined in the acid-soluble fraction of an aliquot of homogenate obtained after precipitation with $5 \%$ perchloric acid. The radioactivity was counted in dioxane scintillator (5g PPO, $0.250 \mathrm{~g}$ POPOP, $100 \mathrm{~g}$ naphthalene) with a Beckman LS - 7800 counter (USA).

1.4. Determination of the rate of the DNA synthesis in the liver and spleen. One hour before slaughtering all the animals were injected with $30 \mathrm{MBq}$ of ${ }^{3} \mathrm{H}$-thymidine per $100 \mathrm{~g}$ of body mass. Animals were euthanized with ether anesthesia in all cases at the same time (from 9 to 10 hours). The liver was perfused with physiological saline cooled to $4{ }^{\circ} \mathrm{C}$. The liver and spleen were removed, the tissue was forced through a press and homogenized in the reagent $\mathrm{A}\left(0.25 \mathrm{M}\right.$ of sucrose, $0.05 \mathrm{M}$ of $\mathrm{KCl}, 0.005 \mathrm{M}$ of $\mathrm{MgCl}_{2}$ on tris- $\mathrm{HCl}$ buffer, $\mathrm{pH}$ 7.6). The homogenate was centrifuged for $10 \mathrm{~min}$ at $3000 \mathrm{~g}\left(4^{\circ} \mathrm{C}\right)$. The sediment was used to produce cell nuclei. The DNA was isolated from the nuclei, its concentration and the specific radioactivity (SR) was determined according to [19]. The SR DNA of precursor in all cases was the same.

Heterosides were injected intraperitoneally every 24 hours to animals with induced hepatitis at doses of 4.8 and $12 \mathrm{mg} / 100 \mathrm{~g}$ of a body mass, always at 9 o'clock in the morning before meals to assess the impact of heteroside 321 on the studied parameters. As a control, the animals with hepatitis were used. All experiments were done at least three times and the results statistically processed using Student's criterion [20]

\section{Results And Discussion}

Local liver hyperthermia $\left(45^{\circ} \mathrm{C}-10 \mathrm{~min}\right)$ was followed by necrosis of some cells, blood disorder and the development of the inflammatory response, manifested as typical autotoxic hepatitis [21]. The level of disease development was determined by the content of the connective tissue and the abuse of detoxification function. After 48 hours of the liver local hyperthermia the content of hydroxyproline (collagen precursor) in the liver tissue was increased by $55 \%$ and the duration of hexenal sleep, which indicates the degree of violation of xenobiotic detoxification function increased by $40 \%$ (Figure 1 ).
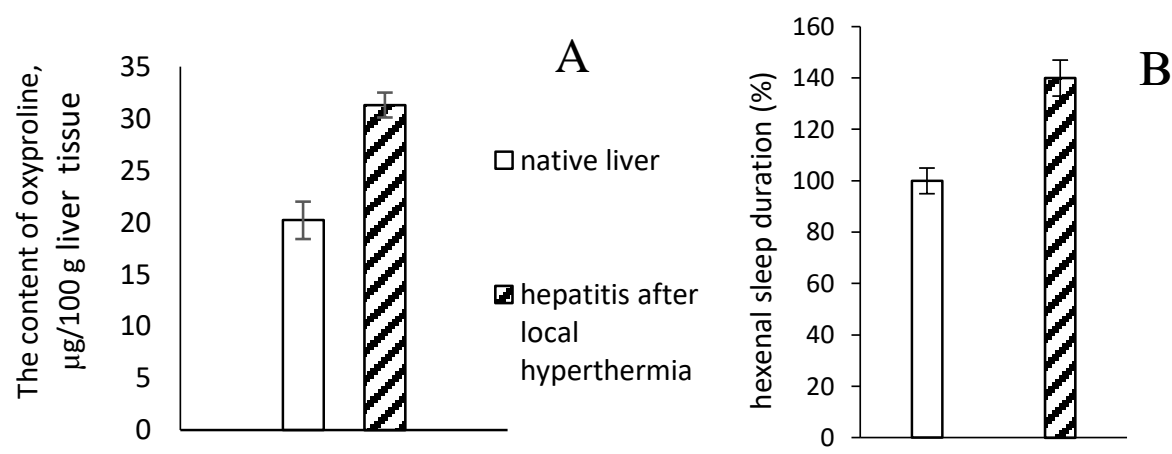

Fig. 1.The content of oxyproline ( $\mu \mathrm{g} / 100 \mathrm{~g}$ liver tissue) (A) in native liver and 48 hours after local hyperthermia (2/3 liver mass in $45{ }^{\circ} \mathrm{C} 10 \mathrm{~min}$.) and antitoxic function of liver (B) which is determined by the duration of hexenal sleep animals. Sleep duration in the control group is accepted as $100 \%$. 
Therefore, 2/3 liver mass local hyperthermia oppressed the monooxygenase system of the microsomal membranes and induced an inflammatory process in the organ, as evidenced by the increase in collagen content and duration of the hexenal sleep. These changes have led to a change in the lipid metabolism of the liver, one of its most important functions. It was found that the SR phospholipids, unesterified fatty acids and triacylglycerols in the microsomal liver fractions was increased after local hyperthermia (48 hours after exposure) in 1.5, 2.3 and 2.8 times, respectively (Figure 2).

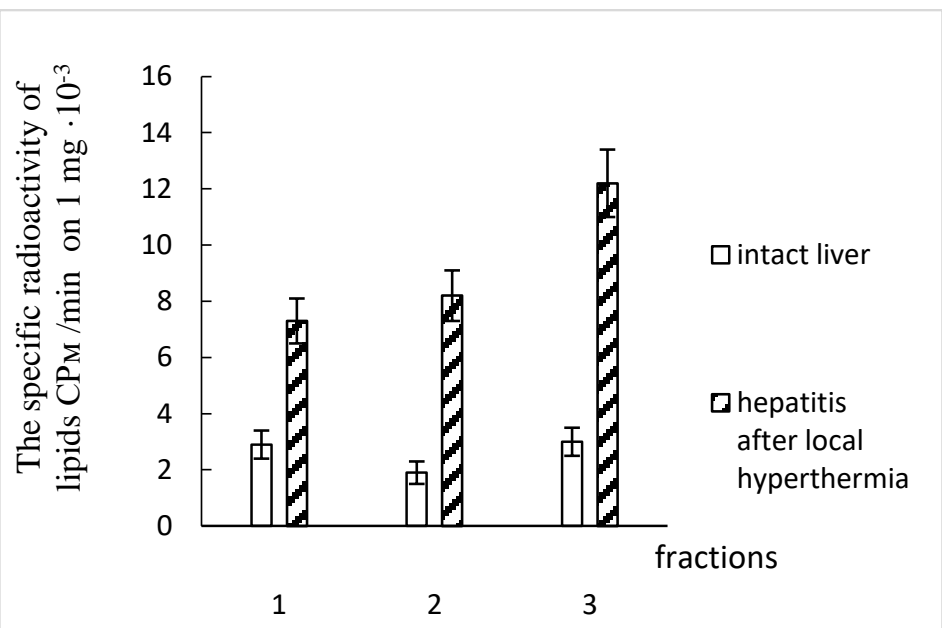

Fig. 2 The specific radioactivity of phospholipids (1), fatty acids (2) and triacylglycerols (3) in the membranes of the endoplasmic reticulum of native liver and liver after local hyperthermia $\left(45^{\circ} \mathrm{C} 10 \mathrm{~min}\right.$.) 48 hours after the influence (presented average values of five independent experiments).

Needless to mention that the radioactivity of labeled precursors (acetate-Na- ${ }^{14} \mathrm{C}$ ) was the same for the intact control animals and after the local hyperthermia. This suggests that the rate of lipid synthesis, membrane liver endoplasmic reticulum 48 hours after local hyperthermia was increased in $1.5-2.8$ times compared with the intact liver. It can be supposed that this will lead to an increase in lipid content in the microsomes. It was found that the content of phospholipids in the liver microsomes after the local hyperthermia increased only by $25 \%$ and the content of non-esterified fatty acids and triacylglycerols did not differ from their content in the microsomes of the control animals (Table 1). It is considered that such "discrepancy" in the rate synthesis and the content of lipids in microsomal fractions is due to increased rate of lipid transport in the cytosol. It appeared that the content of phospholipids in the cytosol fraction 48 hours after local hyperthermia was increased in 2.2 times and triacylglycerols in 4.6times compared to the intact liver (Table 1).

Table 1 the content of different fractions of lipids in the membranes of the endoplasmic reticulum and cytosol ( $\mu \mathrm{g}$ lipids per $1 \mathrm{mg}$ of protein corresponding fractions) in the intact liver and 48 hours after local hyperthermia (liver weight 2.3 at $45^{\circ} \mathrm{C}, 10 \mathrm{~min}$ ).

\begin{tabular}{|c|c|c|c|c|}
\hline \multirow{2}{*}{ Lipid fraction } & \multicolumn{2}{|c|}{$\begin{array}{l}\text { The membrane of the endoplasmic } \\
\text { reticulum }\end{array}$} & \multicolumn{2}{|l|}{ Cytosol } \\
\hline & Intact liver & $\begin{array}{l}\text { The liver after a } \\
\text { local hyperthermia }\end{array}$ & Intact liver & $\begin{array}{l}\text { The liver after a local } \\
\text { hyperthermia }\end{array}$ \\
\hline Phospholipids & $184.5 \pm 7.1$ & $231.5 \pm 5.3^{*}$ & $13.9 \pm 1.2$ & $30.9 \pm 2.5^{*}$ \\
\hline Non-esterifiedfattyacids & $17.2 \pm 1.1$ & $16.1 \pm 1.1$ & $14.2 \pm 1.3$ & $13.7 \pm 0.96$ \\
\hline Triacylglycerol & $32.1 \pm 1.6$ & $35.1 \pm 2.2$ & $40.1 \pm 2.9$ & $186.5 \pm 16.7^{*}$ \\
\hline
\end{tabular}

*Differences between the intact liver and liver after a local hyperthermia

The obtained results suggest that local liver hyperthermia was accompanied with induction of the lipid synthesis in endoplasmic reticulum membranes and the increased transport rate of not labeled lipids into the cytosol i.e. synthesized to radioactive labeling.

As it is known, the intracellular lipid transport is regulated by the lipid-carrying proteins. In this case, it can be expected that their content or lipid transfer efficiency from the membranes to the cytosol can be multiply increased. Determination of the lipid-carrying cytosol proteins showed that their contents did not differ in animals with an intact liver and a liver after the local hyperthermia (Table 2). However content of lipids per 1 $\mathrm{mg}$ of lipid-containing proteins, i.e. "loading" of lipids was 3.6 times higher than in the intact liver cells (Table 2).

Therefore, the effectiveness of the lipid transfer by lipid-carrying proteins after local hyperthermia increased multiply. 
Table 2 The content of lipid-containing proteins carrying the cytosol ( $\mu \mathrm{g}$ per $1 \mathrm{~g}$ of cytosolic proteins) and "loading" lipid ( $\mu \mathrm{mg} / \mathrm{mg}$ protein) lipid carrying proteins. Presented the average values from 5 independent experiments

\begin{tabular}{|l|l|l|}
\hline Experimental variant & The content of proteins carrying lipids & $\begin{array}{l}\text { The content of lipids in proteins carrying } \\
\text { lipids }\end{array}$ \\
\hline Intact liver & $442.1 \pm 11.2$ & $35.11 \pm 2.5$ \\
\hline The liver after a local hyperthermia & $386.0 \pm 9.2$ & $128.4 \pm 8.9^{*}$ \\
\hline
\end{tabular}

*Differences between the intact liver and liver after a local hyperthermia

Therefore, local hyperthermia $\left(45^{\circ} \mathrm{C}-10 \mathrm{~min}\right.$ ) of $2 / 3$ liver mass was accompanied by accumulation of collagen in the liver, increased rate of lipids synthesis in the membranes of the endoplasmic reticulum and rapid transport of lipids with further accumulation in the cytosol. This shows a rapid (already after 24-48 hours) development of the inflammatory process in the liver after the local hyperthermia. As already mentioned, the development of the inflammatory process in the liver may lead to cirrhosis or to the formation of a liver functional activity loss, or to its regeneration by inducing and reparative regeneration. During the initial stages of hepatitis (24-96 hours) rhythmic changes in the rate of synthesis of liver DNA was observed. Thus, SR of DNA liver cells of control animals increased by $34 \%$ after 72 hours of local hyperthermia, compared to 24-48 hours and was reduced by $43 \%$ after 96 hours compared to 72 hours after hyperthermia (Figure 3), indicating a compensatory regeneration of the liver. Due to the leading role of immune system (cellular immunity) in the process of a general protection of the organism and then the local regeneration of organs and tissues it occurred to be appropriate to study the dynamics of the activity of lymphoid tissue in the spleen on the background of autotoxic hepatitis. The studies have shown that DNA SR in spleen cells of the control animals with autotoxic hepatitis varied rhythmically from 24 to 96 hours after pathology induction. If after 48 hours of DNA SR decreased by $50 \%$ compared to 24 hours, and 72 hours to opposite increased 2 times as compared with the 24 hours and decreased again (Figure 3). Thus, the rhythm of the DNA SR in liver and spleen changed in the control animals with autotoxic hepatitis relatively synchronously (Figure 3 ).
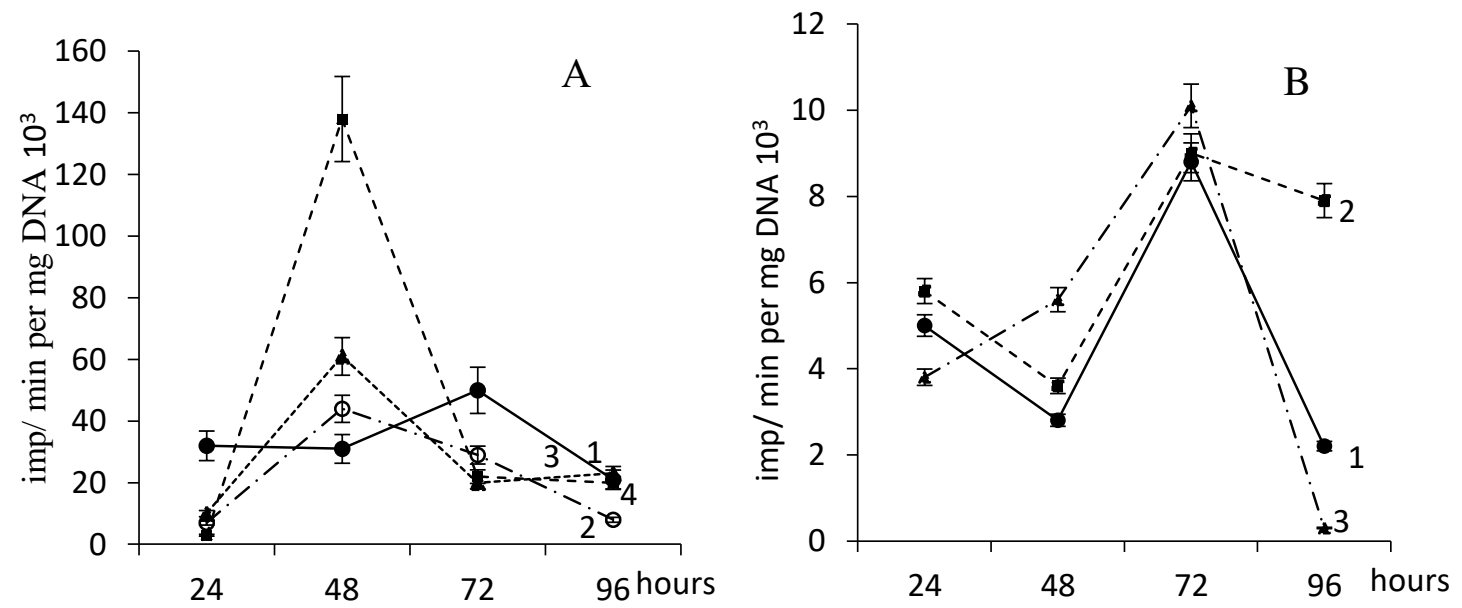

Figure3.The DNA specific radioactivity in liver cells of animals this experimental hepatitis (1) and the influence of the Heteroside-321 in dosages 4 (2), 8 (3) and 12 (4) mg per $100 \mathrm{~g}$ of animal body mass on this parameter

The established fact can be explained by the depletion of the energy and plastic resources or thermal stress, followed by intoxication. Both in one and in the other case a violation of energy metabolism is the determining factor. To test this assumption, heterosides synthesized in our laboratory were used as regulators of proliferative processes in the liver on the background of autotoxic hepatitis. This substances on one hand have shown high efficacy in the activation of enzymatic processes of glycolysis and glycogenesis (basic mechanisms of energy of all tissues), and on the other raised cell resistance to thermal stress [22]. It was found that 24 hours after heteroside 321 injection at doses of 4.8 and $12 \mathrm{mg} / 100 \mathrm{~g}$ of body weight the DNA SR in liver cells was less in 3 times compared to the control group, irrespective of their dosage. Heterosides reinjection at the same dose resulted to a dose-dependent significant increase in the DNA synthesis rate by $30 \%$ at a dose of $4 \mathrm{mg} / 100$ $\mathrm{g}$, in 2 and 3.8 times at the doses of 8 and $12 \mathrm{mg} / 100 \mathrm{~g}$, respectively. After the third heterosides injection (72 hours after induction of hepatitis) the DNA SR again was significantly lower than the corresponding time control. Additional 4-thinjection of heterosides to experimental animals with hepatitis showed no effect on the DNA SR in the liver cells (Figure 3). Thus, heterosides injection every 24 hours to animals with hepatitis accelerated the rate of DNA synthesis. Under similar experimental conditions heterosides injection to animals in 
a dose of $12 \mathrm{mg} / 100 \mathrm{~g}$, has a less pronounced effect on the DNA SR in spleen cells as compared with control variant, retaining rate of the DNA synthesis. As is already noted, during autotoxic hepatitis two variants of molecular events can be observed: necrosis, turning into chronic hepatitis, or induction of liver regeneration. Depending on the ratio of these processes pathological processes or restore physiologic function can be formed. The results of this work indicate that heterosides after several consecutive injections of animals with hepatitis influence on the "choice" of response, increasing proliferative processes in the damaged tissue. Mechanisms of heterosides action on liver function are not yet clear, but it can be supposed that these compounds have a regulatory effect on energy metabolism, metabolism of proteins and nucleic acids. Therefore, heterosides are promising pharmacological substances, which can be widely used, particularly in hepatology.

\section{References}

[1] Manns, M.P; Wedemeyer, H.and Cornberg, M.(2006): Treating viral hepatitis C: efficacy, side effects, and complications. Gut. 55:1350-9.

[2] Behrouzkia, Z; Joveini, Z; Keshavarzi, B; Eyvazzadeh, N. and Aghdam, R.Z. (2016): Hyperthermia: How Can It Be Used? Oman Med J. 31(2):89-97. doi: 10.5001/omj.2016.19.

[3] Datta, N.R; Ordóñez, S.G; Gaipl, U.S; Paulides, M.M; Crezee, H, Gellermann J, Marder D, Puric E, Bodis S. 2015. Local hyperthermia combined with radiotherapy and-/or chemotherapy: recent advances and promises for the future. Cancer Treat Rev. 41742-53. doi: 10.1016/j.ctrv.2015.05.009. Epub 2015 May 27.

[4] Rao, W; Deng, Z.S; and Liu J. (2010):A review of hyperthermia combined with radiotherapy /chemotherapy on malignant tumors. Crit Rev Biomed Eng. 38:101-16. Review

[5] Schildkopf, P; Ott, O.J; Frey, B; Wadepohl, M; Sauer, R; Fietkau, R; and Gaipl, U.S.(2010):Biological rationales and clinical applications of temperature controlled hyperthermia--implications for multimodal cancer treatments. Curr Med Chem. 17: 3045-57. Review.

[6] Partanen, A; Tillander, M; Yarmolenko, P.S; Wood, BJ; Dreher, M.R. and Kohler, M.O.(2013): Reduction of peak acoustic pressure and shaping of heated region by use of multifoci sonications in MR-guided high-intensity focused ultrasound mediated mild hyperthermia. Med Phys. 40:013301. doi: 10.1118/1.4769116.

[7] Hurwitz, M.D. (2010): “Today's thermal therapy: Not your father's hyperthermia: Challenges and opportunities in application of hyperthermia for the 21st century cancer patient.” Am. J. Clin. Oncol. 33, 96-100. doi 10.1097/COC.0b013e3181817a75.

[8] Leon, L.R and Helwig, B.G. (2010): Heat stroke: Role of the systemic inflammatory response Journal of Applied Physiology. 109 (6): 1980-1988. DOI: 10.1152/japplphysiol.00301.2010.

[9] Sharma, S; Rohilla, M.S. and Tiwari, P.K. (2007): Developmental and hyperthermia-induced expression of the heat shock proteins HSP60 and HSP70 in tissues of the housefly Musca domestica: an in vitro study. Genet. Mol. Biol. 30:159-168. doi.org/10.1590/S1415-47572007000100027.

[10] Hall, E.J. and Giaccia, A.J.(2012): Radiobiology for the Radiologist. 7th ed., Philadelphia. Wolters Kluwer Health/Lippincott Williams \& Wilkins. p. 481.

[11] Rieder, C.L. and Cole, R.W. (2002): Cold-Shock and the Mammalian Cell Cycle. Cell Cycle. 1:168-174, DOI: 10.4161/cc.1.3.119.

[12] Bozhkov AI, Shereshevskaya TsM. 1993. Thermoresistance of liver cell membrane linear and hybrid rats. Tsytologiya I Genetika (in Russian) 27, 3-7.

[13] Bozhkov, A.I; Krasnopolsky, Yu.M; Asadova, M.K; Mogilyanskaya, S.M; Dlubovskaya, V.L. and Menzeleev, R.F. (1993): Effect of exogenous lipids on functional activity of liver tissue in experimental hepatitis. Voporosy meditsinskoy khymii (in Russian) 39: 41-43.

[14] Ignat'eva, N.Yu; Danilov, N.A; Averkiev, S.V; Obrezkova, M.V; Lunin, V.V. and Sobol, E.N.(2007): Determination of Hydroxyproline in Tissues and the Evaluation of the Collagen Content of the Tissues, J Anal Chem, 62: 51-57.

[15] Kipenko, A.V; Penniyaynen, V.A; Lopatina, E.V; Tsyrlin, V.A; Lobov, G.I. and Krylov, B.V. (2010): Effect of anoceptin on detoxifying function of the liver.Bull Exp Biol Med. 150: 53-4.

[16] Kamatch, S.A. and Narayan, K. A. (1972): Interaction of Ca2+ with endoplasmic reticulum of rat liver: a standard procedure for the isolation of microsomes. Anal. Biochem, 48 (1): 53-61.

[17] Bozhkov, A.I. and Dlubovskaya, V.L. (1995): Accumulation of lipids in of liver cells cytosol after local hyperthermia and partial hepatectomy. Biochemistry, 60 (11): 1816-1824 (in Russian).

[18] Jork, H; Funk, W; Fischer, W. and Wimmer H. (1994): Thin-Layer Chromatography: Reagents and Detection Methods, Volume 1b, VCH, Weinheim.

[19] Bozhkov, A.I; Shentseva, E.A; Shevtsova, M.Ya; Malyshev, A.B. and Sklyar, A.I.(1995): Influence of the ceylon-containing fraction on passage of the S-period of the cell cycle in the regenerating liver. Biochemistry. 60(4): 610-616. (in Russian).

[20] Zimmerman, D.W. (1997): A Note on Interpretation of the Paired-Samples t Test. Journal of Educational and Behavioral Statistics, 22 (3): 349-360. doi:10.3102/10769986022003349. JSTOR 1165289.

[21] Kang, S. H. et al. (2008): Clinical characteristics of 159 cases of acute toxic hepatitis. The Korean journal of hepatology.14 (4): $483-$ 492.

[22] Kabachny, V.I. and Gorbunova N.I. (2004): Derivatives of heterosides - effective additives to cryoprotective media. Problems of cryobiology. 2: 28-35. 